\title{
Outcome of gastric cancer in the elderly: a population-based evaluation of the Munich Cancer Registry
}

\author{
Anne Schlesinger-Raab ${ }^{1} \cdot$ André L. Mihaljevic $^{2} \cdot$ Silvia Egert $^{3}$ • \\ Rebecca Emeny ${ }^{1} \cdot$ Karl-Walter Jauch $^{4} \cdot$ Jörg Kleeff $^{5}$. \\ Alexander Novotny ${ }^{5}$. Natascha C. Nüssler ${ }^{6} \cdot$ Miriam Rottmann $^{1}$. \\ Wolfgang Schepp ${ }^{7} \cdot$ Wolfgang Schmitt $^{8} \cdot$ Gabriele Schubert-Fritschle $^{1} \cdot$ \\ Bernhard Weber $^{9} \cdot$ Christoph Schuhmacher $^{10} \cdot$ Jutta Engel $^{1}$
}

Received: 26 February 2014/ Accepted: 23 July 2015/Published online: 11 August 2015

(c) The International Gastric Cancer Association and The Japanese Gastric Cancer Association 2015

\begin{abstract}
Background Gastric cancer accounts for $5 \%$ of cancer deaths. Proportions of older stomach cancer patients are increasing. Despite the still poor prognosis, standardised treatment has achieved improvements; nonetheless it is questionable whether all age groups have benefitted. Age and outcome need to be examined in a population-based setting.

Methods Analyses included Munich Cancer Registry (MCR) data from 8601 invasive gastric cancer patients, diagnosed between 1998 and 2012. Tumour and therapy characteristics and outcome were analysed by two age groups ( $<70$ vs. $\geq 70$ years). Survival was analysed using the Kaplan-Meier method and relative survival was computed as an estimation for cancer-specific survival.
\end{abstract}

A.L. Mihaljevic was formerly affiliated with Department of Surgery, Klinikum Rechts der Isar, Technische Universität München, Munich, Germany.

Anne Schlesinger-Raab

schlesi@ibe.med.uni-muenchen.de

1 Munich Cancer Registry (MCR), Munich Tumour Centre (TZM), Department of Medical Informatics, Biometry and Epidemiology (IBE), Klinikum Großhadern, LudwigMaximilians-University (LMU), Marchioninistr. 15, 81377 Munich, Germany

2 Department of Surgery, Heidelberg University Hospital, Heidelberg University, Heidelberg, Germany

3 Münchner Studienzentrum (MSZ), Klinikum rechts der Isar, Technische Universität München, Munich, Germany

4 Klinikum Großhadern, Ludwig-Maximilians-University (LMU), Munich, Germany

5 Department of Surgery, Klinikum Rechts der Isar, Technische Universität München, Munich, Germany
Additional landmark analyses were conducted by calculating conditional survival of patients who survived more than 6 months.

Results Fifty-nine per cent of the cohort were $\geq 70$ years old. These patients had tumours with a slightly better prognosis and were treated with less radical surgery and adjuvant therapy than younger patients. The 5-year relative survival was $40 \%$ for the youngest ( $<50$ years) and $23 \%$ for the oldest patients ( $\geq 80$ years). Survival differences were diminished or eliminated after landmark analyses:

The 5-year relative survival in age groups 50-59, 60-69 and 70-79 years was comparable (between 48 and $49.6 \%)$ and slightly worse in the youngest and oldest (45\%), which may be explained by more aggressive tumours and effects of cellular senescence, respectively.

Conclusion The treatment and care of elderly gastric cancer patients in the MCR catchment area seems appropriate: if a patient's general condition allows oncologic

6 Department of Surgery, Klinikum Neuperlach, Städtisches Klinikum München, Munich, Germany

7 Department of Gastroenterology, Hepatology and Gastrointestinal Oncology, Klinikum Bogenhausen, Städtisches Klinikum München, Munich, Germany

8 Department of Gastroenterology, Klinikum Neuperlach, Städtisches Klinikum München, Munich, Germany

9 Department of Internal Medicine, Klinik Bad Trissl, Oberaudorf, Germany

10 Medical Faculty, Technische Universität München, Munich, Germany 
resection and chemotherapy, it is conducted and the result is comparable between age groups.

Keywords Gastric cancer - Stomach cancer - Elderly . Cancer registry $\cdot$ Comparative effectiveness research

\section{Introduction}

Gastric cancer incidence and mortality in Germany have decreased over more than 3 decades; however, it is still accountable for 3 and $3.7 \%$ of new cancer cases and for 4.6 and $5.1 \%$ of cancer deaths in females and males, respectively [1]. Because of its peak incidence in the 7th decade in males and 8th and 9th decades in females [2], the proportion of older patients with gastric cancer will increase with the expanding older population in industrial countries $[3,4]$.

With knowledge of the poor prognosis of gastric cancer, the National German Guideline "Diagnosis and Treatment of Oesophagogastric Cancer" was published in 2011 [5]. Besides the unquestioned procedure of complete tumour resection in localised disease by gastrectomy or partial gastric resection in selected cases, further recommendations concerning adjuvant and neoadjuvant therapies were made. The successful implementation of recommended treatment procedures with high levels of evidence aims at improving population-based outcomes, e.g. survival. The effect of multimodal therapy in gastric cancer, however, has not yet been studied in a large-scale, population-based setting. Furthermore, the development of guidelines is based on randomised clinical trials (RCT), if available. However, elderly patients with gastric cancer have been underrepresented or excluded in RCTs [6].

In this context, comparative effectiveness research (CER) has become increasingly important in oncology because it strives to compare the benefits and harms of diagnostic, prognostic and therapeutic strategies in terms of effectiveness in actual, representative, health care situations. CER also aims to help clinicians and health care policy makers to reach informed decisions [7]. Of course, prospective randomised controlled clinical trials (RCTs) remain the methodical gold standard, especially for the evaluation of new therapeutic agents. In addition, RCTs provide high internal validity. However, because of restrictive inclusion criteria in RCTs, the results are often not representative for the general population and can therefore not be transferred to routine care, particularly among the elderly. Therefore, observational populationbased cancer registry data should be consulted to evaluate the effects of guidelines [8]. Already existing registry databases such as Surveillance, Epidemiology, and End Results (SEER), the Cancer Research Network or National
Cancer Base provide large sample sizes and long-term follow-up [9].

Significant age-based variations in gastric cancer surgery and adjuvant treatment of the elderly were shown on the basis of a SEER database analysis [10]. On the other hand, other studies did not find significant differences in cancer-specific survival in younger and older age groups if curative surgery had been conducted [11-16].

Hence, the objective of this study is to survey tumour characteristics, treatments and outcomes of gastric cancer by age strata in a German population-based setting.

\section{Methods}

\section{Data collection}

The Munich Cancer Registry (MCR) is the populationbased clinical cancer registry of Upper Bavaria and part of Lower Bavaria (Southern Germany). Its catchment area was enlarged from 2.3 million inhabitants to 3.8 million in 2002 and to 4.6 million in 2007. Pathology reports for solid tumours from all pathology laboratories in this catchment area are available. From these reports, the total number of gastric cancer patients in the region is systematically assessed and the main prognostic factors ascertained. In parallel, clinicians complete standardised forms concerning patients' domicile, age, primary disease characteristics such as TNM stage, histology, grade and therapies. Additionally, the life status of patients with a cancer diagnosis is maintained systematically through death certificates. Thus, active follow-up data are available for about $95 \%$ of all cases.

\section{Patient sample}

A total of 11,124 patients with residence in the catchment area were diagnosed with a malignant gastric tumour over the 15-year study period from 1998 to 2012 (Fig. 1). Patients with an in situ carcinoma, neuroendocrine tumour, sarcoma or lymphoma were excluded as well as death certificate-only cases (DCO, 10.2\%). The analyses of the epidemiological cohort of 8601 patients provide a current and population-based survey of invasive gastric cancer.

Patients with evidence of another previous or synchronous malignant tumour were excluded from survival analyses to eliminate overlapping tumour effects. Thus, the cohort for all survival analyses comprises 7196 patients.

Table 1 shows the distribution of cases by years of initial diagnosis: increasing numbers can be seen in 2001/2002 and 2007/2008 when the catchment area was expanded. The numbers of first malignant tumours are presented as well because they provide the cohort for 


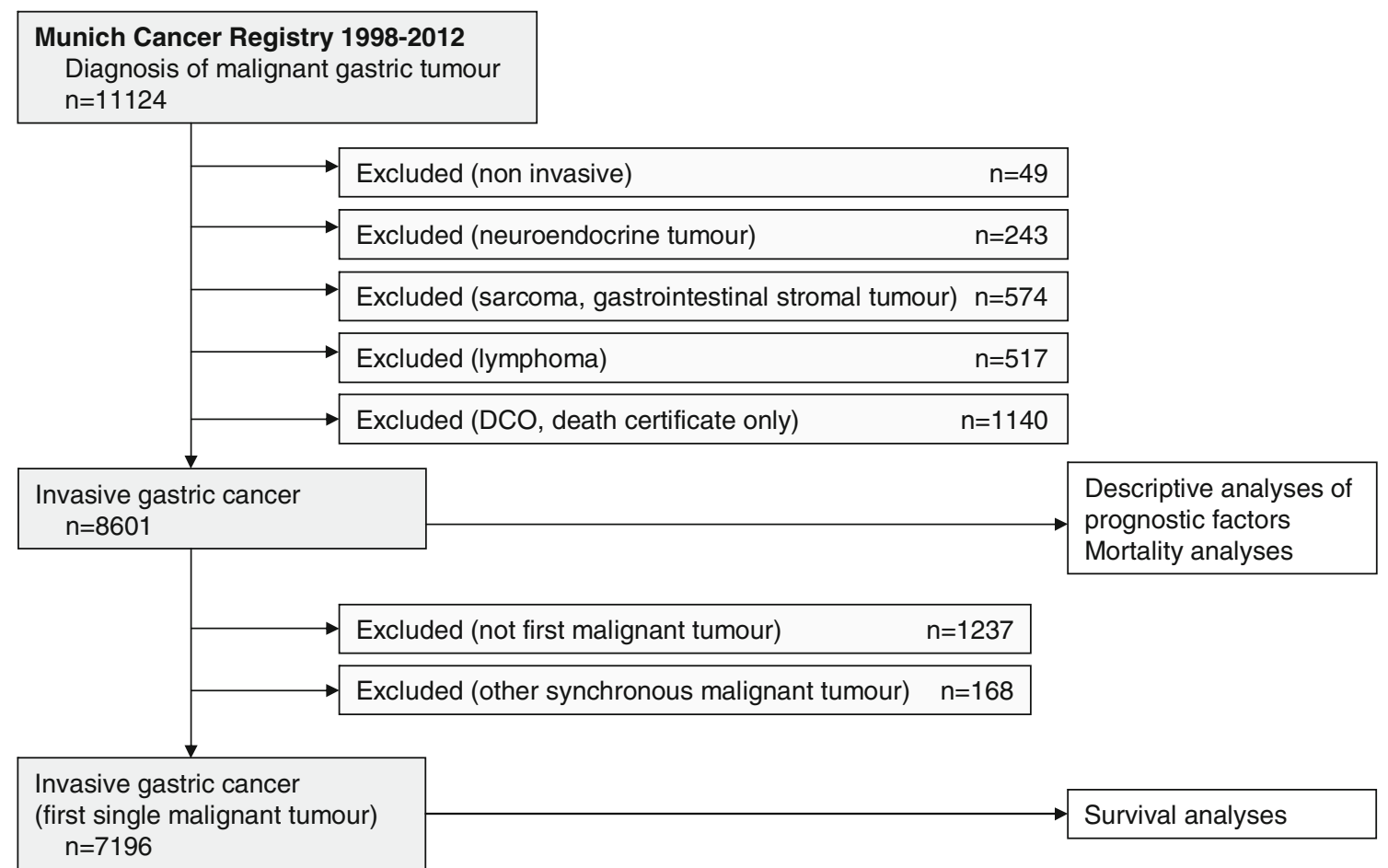

Fig. 1 Study flow chart

Table 1 Numbers of total epidemiologic cohort and first malignant tumour by year (epidemiologic cohort 1998-2012, $n=8601$ )

\begin{tabular}{|c|c|c|c|c|c|c|c|c|}
\hline \multirow[t]{2}{*}{ Years } & \multicolumn{4}{|c|}{ Numbers of epidemiologic cohort } & \multicolumn{4}{|c|}{ Numbers and proportions of first malignant tumour } \\
\hline & $\begin{array}{l}<70 \\
n\end{array}$ & $\begin{array}{l}\geq 70 \\
n\end{array}$ & $\begin{array}{l}\text { Total } \\
n\end{array}$ & $\begin{array}{l}\text { Total cumulative } \\
n\end{array}$ & $\begin{array}{l}<70 \\
n(\%)\end{array}$ & $\begin{array}{l}\geq 70 \\
n(\%)\end{array}$ & $\begin{array}{l}\text { Total } \\
n(\%)\end{array}$ & $\begin{array}{l}\text { Total cumulative } \\
n\end{array}$ \\
\hline 1998 & 187 & 296 & 483 & 483 & $169(90.4)$ & $254(85.8)$ & $423(87.6)$ & 423 \\
\hline $1999 / 2000$ & 329 & 510 & 839 & 1322 & $296(90.0)$ & $418(82.0)$ & $714(85.2)$ & 1137 \\
\hline $2001 / 2002$ & 455 & 638 & 1093 & 2415 & $419(92.1)$ & $538(84.3)$ & 957 (87.6) & 2094 \\
\hline $2003 / 2004$ & 569 & 749 & 1318 & 3733 & $493(86.6)$ & $615(82.1)$ & $1108(84.1)$ & 3202 \\
\hline $2005 / 2006$ & 516 & 777 & 1293 & 5026 & $451(87.4)$ & $624(80.3)$ & $1075(83.1)$ & 4277 \\
\hline $2007 / 2008$ & 608 & 885 & 1493 & 6519 & 527 (86.7) & 696 (78.6) & $1223(81.9)$ & 5500 \\
\hline 2009/2010 & 531 & 761 & 1292 & 7811 & 445 (83.8) & 599 (78.7) & $1044(80.8)$ & 6544 \\
\hline $2011 / 2012$ & 325 & 465 & 790 & 8601 & $285(87.7)$ & 367 (78.9) & $652(82.5)$ & 7196 \\
\hline Total & 3520 & 5081 & 8601 & 8601 & 3085 (87.6) & 4111 (80.9) & 7196 (83.7) & 7196 \\
\hline
\end{tabular}

survival analysis; $84 \%$ of gastric cancers are the patients' first malignant tumour, and $16 \%$ of patients have had other malignomas before.

\section{Number of participating hospitals}

The patients were treated in 64 different surgical and 32 medical hospitals and departments, whereby 24 surgical hospitals provided the documentation for over $85 \%$ of the surgically treated patients and 21 medical hospitals participated in the documentation of over $85 \%$ of the medically treated patients.

\section{Statistics}

The MCR organises data in an Oracle database. Statistical analyses were run in SAS (Statistical Analysis System 9.2). Frequency data were analysed using the chi-square test. The percentages of the presented subcategories were related to the sum of each item with available data; missing values were not taken into account. Conditional (cond.) mortality rates are computed by the Cutler-Ederer method.

Observed (unadjusted overall) survival was estimated by the Kaplan-Meier method and tested with the log-rank test. Relative survival was calculated by the ratio of the 
observed survival rate to the expected survival rate. The expected survival time of age- and gender-matched individuals was calculated using life tables of the general German population. Relative survival can be interpreted as survival from cancer after correction for other causes of death and therefore is used as an estimate for cancerspecific survival. To adjust for effects of age on treatment outcome such as postoperative mortality, a conditional survival analysis was calculated for those who survived at least half a year, according to the landmark method proposed by Anderson et al. [17]. The significance level $\alpha$ was set at 0.05 in all statistical tests.

For the evaluation of elderly patients, cutoffs at 65,70 or 75 years are common in the literature, $[10,12,15,18$, 19]. The $<70$ vs. $\geq 70$ year cutoff was chosen because it is also used for risk assessment in surgery [20, 21]. In addition, survival was examined in age groups of 10 years between the 50th and 80th year to provide further detailed information about the effects of age.

\section{Results}

\section{Patient and tumour characteristics}

The population-based cohort of gastric carcinoma comprises 8601 cases of invasive gastric cancer from 1998 to 2012. The patient characteristics are listed in Table 2 stratified by two age groups: younger than 70 years (median age 61 years, range 19-69 years) vs. 70 years and older (median age 79 years, range 70-102 years). Fifty-seven per cent of the gastric cancer patients were male and $59 \%$ were aged 70 years or older at initial diagnosis. The combined TNM categories showed slightly more advanced stages in the younger age group, e.g. primary distant metastases in $31 \%$ of those younger than 70 years and $23 \%$ in the older age group. Classifications by grade of differentiation and Lauren also showed a higher proportion of tumours with worse prognosis for patients under 70 years, e.g. $76 \%$ of tumours were poor or not differentiated and $48 \%$ were diffuse in the younger vs. 63 and $29 \%$ for undifferentiated and diffuse tumours, respectively, in the older patients. A higher proportion $(33 \%)$ of signet cell carcinoma was found in the younger vs. $19 \%$ in the older age group. Tumour site distribution was somewhat more distal in the elderly.

The distribution of missing values differed by age group as well. Except for the Lauren classification, all tumour characteristics were more often unavailable in the older age group.

\section{Therapy}

Table 3 presents characteristics concerning the gastric cancer therapy. Considerable differences between patients under 70 or 70 and older were found: in patients under 70 years, surgery was performed more often (74 vs. $60 \%$ ), and they received more chemo- or radiotherapy (54\% of the younger patients were treated by surgery only and about $31 \%$ had adjuvant or neoadjuvant radiation therapy or chemotherapy, whereas $80 \%$ of the elderly were treated by surgery only).

The proportion of patients with information about palliative therapy only or missing information was $13 \%$ in the younger age group, but $34 \%$ in the older. Missing values concerning therapy correspond to missing values concerning tumour characteristics, first and foremost the pathological TNM stage. In general, information about outpatient biopsies and treatment without curative intent is more infrequently known.

Oncologic tumour resection was conducted in $67 \%$ of the younger patients (2359 of 3520 ) and in only $52 \%$ of the older patients $(2,638$ of 5,081$)$. In addition, when performed, surgery was more radical in younger cohorts with $59 \%$ gastrectomies and $12 \%$ oesophageal surgery compared to the older patients with 45 and $6 \%$, respectively.

The quality of surgery reflected by the status of residual tumour, however, did not show differences between the age groups. The proportion of R0 resected tumours was more than $80 \%$ in both groups.

\section{Mortality}

Perioperative mortality or mortality after initial diagnosis (in non-surgery cases or cases with missing information about surgery) as presented in Table 4 shows a relevant difference between the younger and older age group: $4.8 \%$ of the younger patients died within 30 days after surgery or initial diagnosis. Of those who are 70 years and older $13.1 \%$ (667 of 5081) died within the first 30 days. Most of these patients (namely 431 of 667; $65 \%$ ) were non-surgery patients.

\section{Survival}

The survival analysis included 7,196 patients with gastric cancer as their first malignant tumour from the years 1998 to 2012. The average and median observation time of the survivors was 64.2 and 56.2 months, respectively. The 5-year overall survival was $28 \%$ and the 5-year relative survival, as an estimate for cancer-specific survival, constituted $33 \%$. 
Table 2 Patient and tumour characteristics by two age groups (epidemiologic cohort 1998-2012, $n=8601$ )

\begin{tabular}{|c|c|c|c|c|c|c|c|}
\hline \multirow{3}{*}{$\begin{array}{l}\text { Age in years } \\
\text { Prognostic factors }\end{array}$} & \multirow{2}{*}{\multicolumn{2}{|c|}{$\begin{array}{l}<70 \\
n=3520\end{array}$}} & \multirow{2}{*}{\multicolumn{2}{|c|}{$\begin{array}{l}\geq 70 \\
n=5081\end{array}$}} & \multirow{2}{*}{\multicolumn{2}{|c|}{$\frac{\text { Total }}{n=8601}$}} & \multirow[t]{3}{*}{$P$ value } \\
\hline & & & & & & & \\
\hline & $n$ & $\%^{\mathrm{a}}$ & $n$ & $\%^{\mathrm{a}}$ & $n$ & $\%^{\mathrm{a}}$ & \\
\hline \multicolumn{8}{|l|}{ Sex } \\
\hline Male & 2250 & 63.9 & 2639 & 51.9 & 4889 & 56.8 & \multirow[t]{2}{*}{$<0.0001$} \\
\hline Female & 1270 & 36.1 & 2442 & 48.1 & 3712 & 43.2 & \\
\hline \multicolumn{8}{|l|}{ T Category (comb.) } \\
\hline $\mathrm{T} 1$ & 579 & 22.5 & 785 & 24.8 & 1364 & 23.7 & \multirow[t]{5}{*}{$<0.0001$} \\
\hline $\mathrm{T} 2$ & 786 & 30.5 & 1074 & 33.9 & 1860 & 32.4 & \\
\hline $\mathrm{T} 3$ & 902 & 35.0 & 939 & 29.6 & 1841 & 32.0 & \\
\hline $\mathrm{T} 4$ & 312 & 12.1 & 372 & 11.7 & 684 & 11.9 & \\
\hline Not available & 941 & 26.7 & 1911 & 37.6 & 2852 & 33.2 & \\
\hline \multicolumn{8}{|l|}{ N Category (comb.) } \\
\hline N0 & 1009 & 36.9 & 1180 & 37.4 & 2189 & 37.2 & \multirow[t]{4}{*}{$<0.0001$} \\
\hline $\mathrm{N}+$ & 1619 & 59.2 & 1740 & 55.2 & 3359 & 57.1 & \\
\hline NX & 105 & 3.8 & 232 & 7.4 & 337 & 5.7 & \\
\hline Not available & 787 & 22.4 & 1929 & 38.0 & 2716 & 31.6 & \\
\hline \multicolumn{8}{|l|}{ M Category (primary) } \\
\hline M1 & 1099 & 31.2 & 1159 & 22.8 & 2258 & 26.3 & $<0.0001$ \\
\hline \multicolumn{8}{|l|}{ UICC Stage (comb.) } \\
\hline I & 784 & 26.2 & 1102 & 30.6 & 1886 & 28.6 & \multirow[t]{5}{*}{$<0.0001$} \\
\hline II & 612 & 20.5 & 610 & 16.9 & 1222 & 18.5 & \\
\hline III & 331 & 11.1 & 511 & 14.2 & 842 & 12.8 & \\
\hline IV & 1265 & 42.3 & 1377 & 38.3 & 2642 & 40.1 & \\
\hline Not available & 528 & 15.0 & 1481 & 29.1 & 2009 & 23.4 & \\
\hline \multicolumn{8}{|l|}{ Grade } \\
\hline G1 & 108 & 3.3 & 276 & 5.9 & 384 & 4.8 & \multirow[t]{4}{*}{$<0.0001$} \\
\hline $\mathrm{G} 2$ & 699 & 21.2 & 1468 & 31.6 & 2167 & 27.3 & \\
\hline G3-4 & 2493 & 75.6 & 2905 & 62.5 & 5398 & 67.9 & \\
\hline Not available & 220 & 6.3 & 432 & 8.5 & 652 & 7.6 & \\
\hline \multicolumn{8}{|l|}{ Lauren classification } \\
\hline Intestinal & 1238 & 46.6 & 2630 & 67.8 & 3868 & 59.2 & \multirow[t]{4}{*}{$<0.0001$} \\
\hline Diffuse & 1286 & 48.4 & 1124 & 29.0 & 2410 & 36.9 & \\
\hline Mixed & 133 & 5.0 & 127 & 3.3 & 260 & 4.0 & \\
\hline Not available & 863 & 24.5 & 1200 & 23.6 & 2063 & 24.0 & \\
\hline \multicolumn{8}{|l|}{ Histology } \\
\hline Adenocarcinoma & 2245 & 64.9 & 3923 & 78.9 & 6168 & 73.2 & \multirow[t]{4}{*}{$<0.0001$} \\
\hline Signet cell carcinoma & 1122 & 32.5 & 920 & 18.5 & 2042 & 24.2 & \\
\hline Other & 90 & 2.6 & 131 & 2.6 & 221 & 2.6 & \\
\hline Not available & 63 & 1.8 & 107 & 2.1 & 170 & 2.0 & \\
\hline \multicolumn{8}{|l|}{ Anatomic site } \\
\hline GEJ, cardia & 764 & 24.0 & 812 & 18.7 & 1576 & 21.0 & \multirow[t]{5}{*}{$<0.0001$} \\
\hline Corpus, fundus, others & 1548 & 48.7 & 2071 & 47.7 & 3619 & 48.1 & \\
\hline Antrum, pylorus & 866 & 27.3 & 1458 & 33.6 & 2324 & 30.9 & \\
\hline Not available & 342 & 9.7 & 740 & 14.6 & 1082 & 12.6 & \\
\hline Total & 3520 & 40.9 & 5081 & 59.1 & 8601 & 100 & \\
\hline
\end{tabular}

comb. combined cT/pT or $\mathrm{cN} / \mathrm{pN}, G E J$ gastro-oesophageal junction

a Missing values were excluded from calculations of frequency distribution, column percentage can differ slightly from $100 \%$ because of rounding 
Table 3 Therapy by two age groups (epidemiologic cohort 1998-2012, $n=8601$ )
Table 4 Mortality (postsurgery or since initial diagnosis) by age

\begin{tabular}{|c|c|c|c|c|c|c|c|}
\hline \multirow{3}{*}{$\begin{array}{l}\text { Age in years } \\
\text { Therapy characteristics }\end{array}$} & \multirow{2}{*}{\multicolumn{2}{|c|}{$\begin{array}{l}<70 \\
n=3520\end{array}$}} & \multirow{2}{*}{\multicolumn{2}{|c|}{$\begin{array}{l}\geq 70 \\
n=5081\end{array}$}} & \multirow{2}{*}{\multicolumn{2}{|c|}{$\begin{array}{l}\text { Total } \\
n=8601\end{array}$}} & \multirow[t]{3}{*}{$P$ value } \\
\hline & & & & & & & \\
\hline & $n$ & $\%^{\mathrm{a}}$ & $n$ & $\%^{\mathrm{a}}$ & $n$ & $\%^{\mathrm{a}}$ & \\
\hline Therapy & \multicolumn{2}{|l|}{$n=3520$} & \multicolumn{2}{|l|}{$n=5081$} & \multicolumn{2}{|l|}{$n=8601$} & \\
\hline Surgery \pm CTX/RTX/RCTX & 2593 & 73.7 & 3033 & 59.7 & 5626 & 65.4 & $<0.0001$ \\
\hline No surgery/palliation/not available & 927 & 26.3 & 2048 & 40.3 & 2975 & 34.6 & \\
\hline \multicolumn{8}{|l|}{ Therapy } \\
\hline Surgery only & 1655 & 54.1 & 2682 & 80.3 & 4337 & 67.8 & $<0.0001$ \\
\hline Surgery + CTX/RCTX (neoadj.) & 544 & 17.8 & 193 & 5.8 & 737 & 11.5 & \\
\hline Surgery + Chemo (adj.) & 239 & 7.8 & 129 & 3.9 & 368 & 5.8 & \\
\hline Surgery + RTX/RCTX (adj.) & 155 & 5.1 & 29 & 0.9 & 184 & 2.9 & \\
\hline CTX only & 408 & 13.3 & 255 & 7.6 & 663 & 10.4 & \\
\hline RTX/RCTX only & 58 & 1.9 & 51 & 1.5 & 109 & 1.7 & \\
\hline Palliation/not available & 461 & 13.1 & 1742 & 34.3 & 2203 & 25.6 & \\
\hline Surgery & $n=2593$ & & $n=3033$ & & $n=5626$ & & \\
\hline \multirow[t]{2}{*}{ Oncologic resection } & 2359 & 91.0 & 2638 & 87.0 & 4997 & 88.8 & $<0.0001$ \\
\hline & $n=2359$ & & $n=2638$ & & $n=4997$ & & \\
\hline Gastrectomy & 1391 & 59.0 & 1180 & 44.7 & 2571 & 51.5 & $<0.0001$ \\
\hline Partial gastric resection & 540 & 22.9 & 978 & 37.1 & 1518 & 30.4 & \\
\hline Surgery incl. oesophageal resection & 272 & 11.5 & 161 & 6.1 & 433 & 8.7 & \\
\hline Others & 156 & 6.6 & 319 & 12.1 & 475 & 9.5 & \\
\hline Surgery & \multicolumn{2}{|l|}{$n=2593$} & \multicolumn{2}{|l|}{$n=3033$} & \multicolumn{2}{|l|}{$n=5626$} & \\
\hline \multicolumn{8}{|l|}{ Residual status } \\
\hline $\mathrm{R} 0$ & 1412 & 82.6 & 1933 & 81.0 & 3345 & 81.7 & 0.1808 \\
\hline $\mathrm{R} 1 / \mathrm{R} 2 / \mathrm{RX}$ & 297 & 17.4 & 454 & 19.0 & 751 & 18.3 & \\
\hline Not available & 884 & 34.1 & 646 & 21.3 & 1530 & 27.2 & \\
\hline Surgery & $n=2593$ & & $n=3033$ & & $n=5626$ & & \\
\hline \multicolumn{8}{|l|}{ Lymphadenectomy } \\
\hline Performed & 1584 & 61.1 & 1464 & 48.3 & 3048 & 54.2 & $<0.0001$ \\
\hline Thereof D1 & 102 & 6.4 & 155 & 10.6 & 257 & 8.4 & $<0.0001$ \\
\hline Thereof D2 & 1087 & 68.6 & 909 & 62.1 & 1996 & 65.5 & \\
\hline
\end{tabular}

a Missing values were excluded from calculations of frequency distribution; column percentage can differ slightly from $100 \%$ because of rounding

CTX chemotherapy, RCTX combined radiochemotherapy, $R T X$ radiation therapy, neoadj. neoadjuvant, adj. adjuvant, incl. including

\begin{tabular}{|c|c|c|c|c|c|c|}
\hline \multirow[t]{2}{*}{ Age in years } & \multicolumn{2}{|c|}{$<70(n=3520)$} & \multicolumn{2}{|c|}{$\geq 70(n=5081)$} & \multicolumn{2}{|c|}{ All $(n=8601)$} \\
\hline & $n$ & $\%$ cond. & $n$ & $\%$ cond. & $n$ & $\%$ cond. \\
\hline \multicolumn{7}{|l|}{ Died within } \\
\hline$\leq 30$ days & 168 & 4.8 & 667 & 13.1 & 835 & 9.7 \\
\hline$>30$ to $\leq 60$ days & 166 & 5.0 & 399 & 9.0 & 565 & 7.3 \\
\hline$>60$ to $\leq 90$ days & 108 & 3.4 & 284 & 7.1 & 392 & 5.5 \\
\hline$>90$ days to $\leq 1$ year & 760 & 24.9 & 1349 & 36.4 & 2109 & 31.2 \\
\hline$>1$ year to $\leq 2$ years & 493 & 22.4 & 618 & 27.4 & 1111 & 24.9 \\
\hline$>2$ years to $\leq 5$ years & 389 & 26.5 & 519 & 36.8 & 908 & 31.5 \\
\hline$>5$ years to $\leq 10$ years & 112 & 17.0 & 233 & 40.7 & 345 & 28.0 \\
\hline$>10$ years to $\leq 16$ years & 18 & 10.9 & 38 & 35.5 & 56 & 20.7 \\
\hline Alive/lost to follow-up & \multicolumn{2}{|l|}{1306} & \multicolumn{2}{|l|}{974} & \multicolumn{2}{|l|}{2280} \\
\hline
\end{tabular}



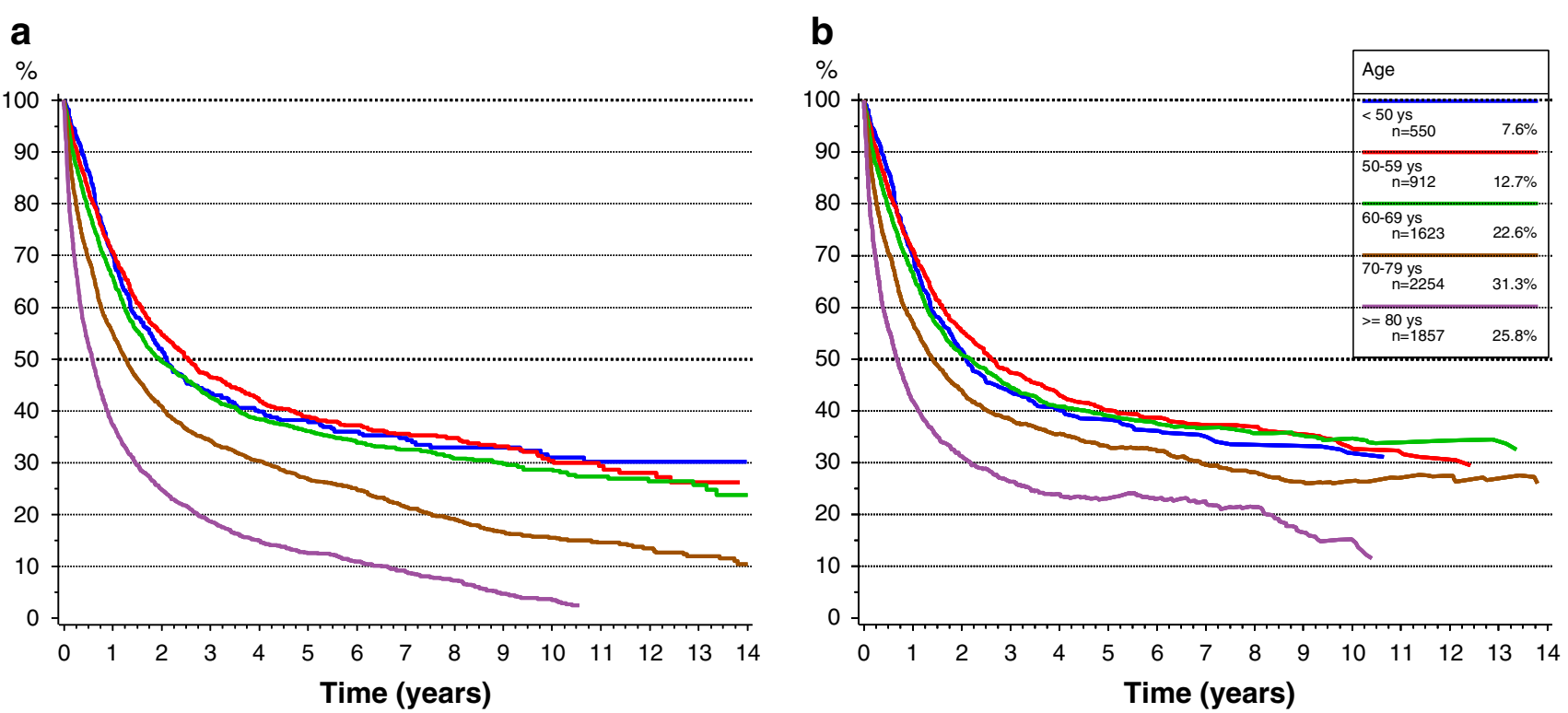

Fig. 2 a, b Overall and relative survival by age $(1998-2012, n=7196)$
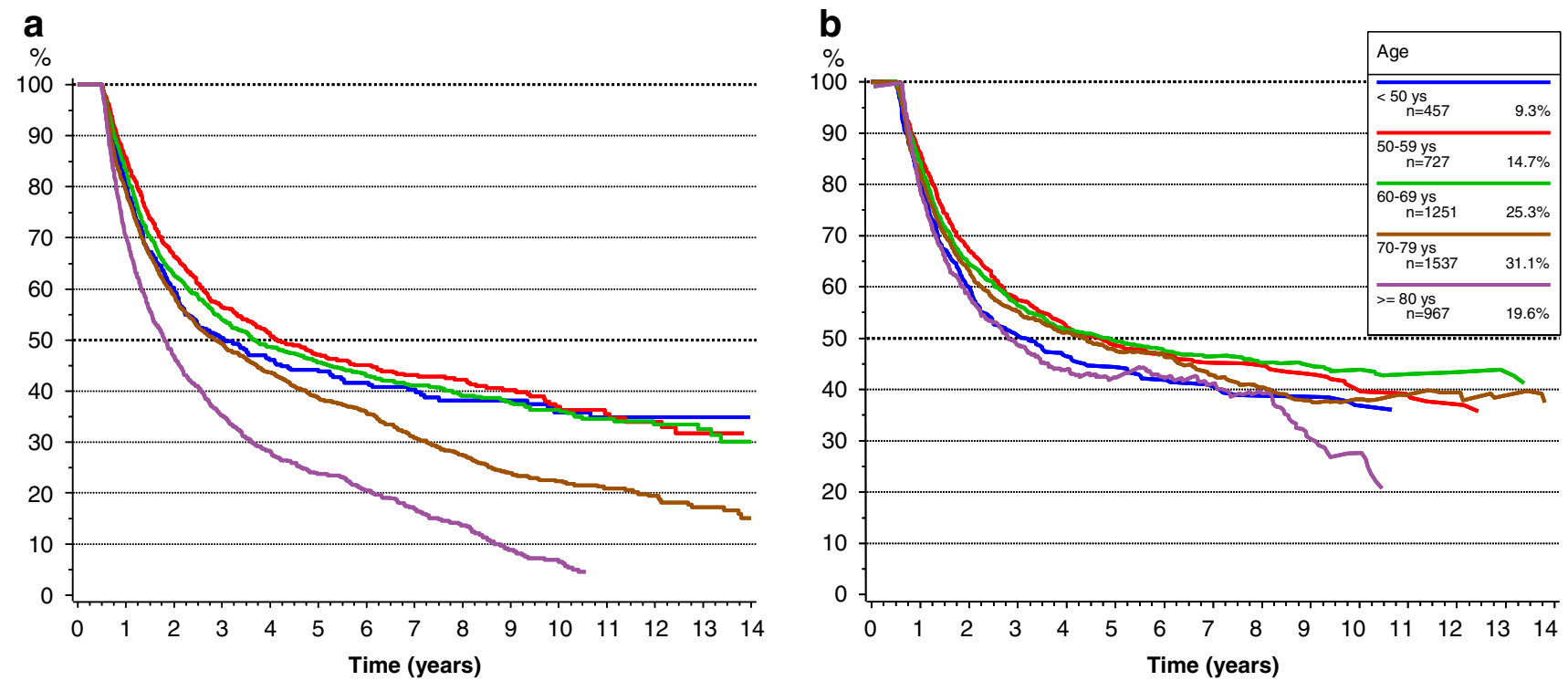

Fig. 3 a, b Conditional overall and relative survival by age group for those patients who survived at least 6 months after diagnosis (1998-2012, $n=4939$ )

Figure $2 \mathrm{a}, \mathrm{b}$ presents the observed and relative survival stratified by five age groups. The observed median survival ranged from 2.5 to 0.6 years and the 5-year relative survival (graph B) was between 40.1 and $23.1 \%$. The survival curves, and especially the relative survival curves, demonstrated first that survival was nearly the same up to an age less than 70 years and that the oldest age group ( $\geq 80$ years) had a considerably worse cancer-specific survival. Second, the survival curves also illustrated that the survival differences were generated in the first and second year and that the curves were more or less collateral and ran parallel from the 2 nd to 3 rd year after diagnosis.

Therefore, a further survival analysis by age groups was done under the condition that patients had survived at least half a year $(n=4939)$. This is presented in Fig. 3a, b. The median and 5-year relative survival in the three age groups 50-59, 60-69 and 70-79 years was comparable, as shown in Graph B: median survival was between 2.9 and 4.1 years and 5-year relative survival was between 47.7 and $49.5 \%$. In addition, the curves of the youngest and oldest age 
groups were quite congruent and slightly worse than in patients aged 60-69, with a 5-year relative survival of 44.3 and $43.3 \%$ for patients up to the 5 th and in the 7 th decade, respectively.

\section{Discussion}

This study presents population-based and representative information on invasive gastric cancer; age and sex distributions are generalisable to all of Bavaria [22] and the relative 5-year-survival of $33 \%$ is comparable to $31 \%$ for the whole of Germany [1]. In comparison to other European countries, the proportion of the elderly $(70+$ years $)$ is less (59 vs. $66 \%$ in the UK [23], $63 \%$ in Sweden [24]). The survival of this cohort is better than in many other European countries and in the USA, which may partially be explained by differences in stage distribution [9, 23-26].

It is widely agreed that the proportion of elderly patients is increasing in oncology. In this setting, it is generally claimed that elderly patients are often provided with substandard chemotherapy or surgical options [19, 27]. A report by Macmillan Cancer Support stated in 2010: "Improvements in mortality have been slower in older people than in younger people. Older people with cancer receive less intensive treatment than younger people. There is increasing evidence that under-treatment of older people may occur" [28]. One reason for under-treatment could be due to clinicians' frequent underestimation of the life expectancy of the elderly; another could be limitations in economic resources. Additionally, the omission of the elderly from clinical trials and the subsequent lack of evidence for treatment of elderly patients have been criticised [18, 29].

Referring to these circumstances, the MCR data also show that elderly patients aged 70 and beyond have more tumours with a better prognosis (less primary M1, more differentiated, more intestinal type) and are also treated less radically with less oncologic resection and fewer adjuvant therapies, and they have worse survival. SEER data also show an increasing proportion of partial gastric resection and a decreasing proportion of adequate lymphonodal evaluation and adjuvant radiation therapy with increasing age [10]. The higher proportion of missing data concerning tumour stage and treatment in the elderly probably points to less treatment with curative intent. Nevertheless, $21 \%$ of the elderly in MCR data have other previous or synchronous malignant tumours at initial diagnosis, which may also influence the primary therapy. In the younger patients this proportion is only about $12 \%$.

This raises the question whether treatment and care of older patients is really worse than those of the younger ones or whether the elderly are treated adequately with consideration of their medical history and comorbidities. Besides second malignancies, many other factors such as comorbidity, decreased functional status, alterations in mental status and an assumed inability to tolerate treatment are all factors that may influence the selection of therapy and thus may affect survival of the elderly [20].

There are some hints within our data that suggest that specific patient cohorts with burdens of comorbidity or bad general conditions account for the observed worse survival of elderly patients rather than the cause being due to poorer health care administered to these elderly patients in general:

At first, the MCR data show that R0 resection is conducted as often in the elderly as in the younger ones if they undergo oncologic tumour resection (81 vs. $83 \%$ ). Furthermore, there is little evidence for differences in surgical techniques, which appear to be independent of the patients' age but rather dependent on tumour localisation. Hence, surgical treatment quality seems to be comparable between the two age groups. Those clinical trials that have analysed surgery in regard to age noted that selected elderly in good general condition and functional, social and mental status benefit from oncologic resection and peri- or postoperative chemotherapy as much as the younger ones [12, 30].

Secondly, the worse survival of elderly patients is primarily due to the mortality within the first 30 days post diagnosis and partly due to mortality within the first half year. This is another hint for different characteristics of the age cohorts, i.e. younger patients in better general condition and the older patients with comorbidities, as well as other complicating circumstances. There is little evidence for differences in surgical techniques that appear to be independent of the patients' age.

Thirdly, the early diverging survival curves also do not offer hints for "better" adjuvant or additive therapy in the younger patients and substandard therapy in the elderly. If this were the case, the curves would diverge much later. In fact, the cohort of elderly patients, with a 30-day mortality of $13 \%$, cannot be comparable to those in clinical trials that present perioperative mortality lower than $3 \%$ [14, 15]. Effects of therapy cannot explain differences like these. The high proportion of non-surgery patients in the early mortality of the elderly of $65 \%$ also supports the assumption of basically different cohorts that demand different indications for therapy: surgery in patients who die within 30 days rightly appears to miss the target of treatment.

The elimination of early mortality by the landmark analysis explicitly reduces the observed survival differences: if patients have survived the first 6 months, an age between 50 to 79 years has no impact on the further survival. Only the youngest $(<50)$ and the oldest $(80+)$ patients have the same, slightly worse survival, presumably 
explained by the more aggressive tumour characteristics in the younger patients and the effects of cellular senescence in the oldest patients [31].

While the arguments are coherent and the study cohort seems to be representative, there are nevertheless some limitations of this study that have to be mentioned, especially the missing information concerning tumour-specific characteristics and therapeutic measures in the older group. However, missing values may indicate that older patients are more often treated without curative intent and surgery is avoided to prevent further complications, whereas the reduction of lifetime may be accepted, an adequate proceeding in palliative situations. Although some information is missing, patients were not excluded from survival analyses because conclusions regarding the effectiveness of the health care system and gastric cancer as a whole are not influenced. Nevertheless, improvement in completeness of registry information would sharpen this population-based instrument for the future. Another very important limiting aspect is the lack of information about comorbidities and patients' general conditions. Comparisons of age groups would be more conclusive with adjustment of these characteristics as well as information on socio-economic circumstances.

\section{Conclusion}

Apparently, a large proportion of older stomach cancer patients is in a difficult situation in which undergoing oncologic surgery can cause death because of perioperative or surgical complications or can increase frailty after gastric resection while treatment by even best supportive palliative care results in death due to tumour growth. Hence, it can be stated that indecisive implementation of guideline recommendations in elderly patient cohorts need not be a sign of deficient health care at all. Rather, the fitness of the older patient must be severely weighed in oncologic treatment decisions. The treatment and care of the elderly gastric cancer patients in the MCR catchment area seem to take place appropriately: if the patient's general condition allows oncologic resection and chemotherapy, it is conducted and the result is comparable across age groups.

Acknowledgments We thank all the hospitals, departments and practitioners that participated in the documentation of the data. In particular we thank the following 24 surgical hospitals and departments that participated in the documentation of $85 \%$ of the presented surgically treated cohort: Klinikum rechts der Isar der TU, Chirurgische Klinik und Poliklinik: Prof. H. Friess; Klinikum der LudwigMaximilians-Universität-Großhadern, Chirurgische Klinik und Poliklinik: Prof. J. Werner, vormals Prof. K.-W. Jauch; Städt Klinikum München-Neuperlach, Klinik für Allgemein- und Viszeralchirurgie, endokrine Chirurgie und Coloproktologie: Prof. N. Nüssler; Städt. Klinikum München-Bogenhausen, Klinik für Allgemein-, Viszeral-,
Gefäß- und Thoraxchirurgie: Dr. R. Schmid, vormals Prof. W. Heitland; Städt. Klinikum München-Harlaching, Klinik für Allgemeinund Viszeralchirurgie und Coloproktologie: Prof. N. Nüssler; Klinikum Traunstein, Abteilung für Allgemein-, Viszeral- und Minimalinvasive Chirurgie: PD Dr. R. J. Schauer; Klinikum Dritter Orden, Klinik für Allgemein-, Viszeral-, Gefäß- und Thoraxchirurgie: Dr. D. Krenz; Klinikum Dachau, Abteilung für Viszeral- und Thoraxchirurgie: Prof. H.-G. Rau; Klinikum Rosenheim, Klinik für Allgemein-, Gefäß- und Thoraxchirurgie: Prof. P. Wagner; Kreisklinikum Altötting, Abteilung für Allgemein-, Viszeral- und Thoraxchirurgie: Prof. J. Roder; Krankenhaus Barmherzige Brüder München, Allgemein- und Viszeralchirurgie: Dr. C. Reuter; Städt. Klinikum München-Schwabing, Klinik für Viszeralmedizin: Prof. H. Waldner; Klinikum Landshut, Chirurgische Klinik I: Prof. F. Löhe; Klinikum Landkreis Erding, Abteilung für Viszeral- und Thoraxchirurgie: Dr. H. Bödecker; Klinikum der Ludwig-Maximilians-Universität-Innenstadt, Chirurgische Klinik und Poliklinik: Prof. W. Mutschler; Klinikum München-Pasing, Chirurgische Klinik: Dr. D. Laqua; Klinikum Freising, Abteilung für Allgemein-, Thorax- und Gefäßchirurgie: Dr. F. Zeller; Rotkreuzkrankenhaus, Chirurgische Abteilung: Prof. H. H. Schoenberg; Klinikum Ingolstadt, Chirurgische Klinik I: Prof. S. B. Hosch; Maria-Theresia-Klinik, Chirurgische Abteilung: Prof. T. F. Hoffmann; Klinikum Garmisch-Partenkirchen, Fachabteilung Allgemein-, Viszeral-, Thorax- und endokrine Chirurgie: PD Dr. H. Vogelsang; Klinikum Fürstenfeldbruck, Fachbereich Allgemein- und Visceralchirurgie: Dr. P. Knapp; Kreisklinik Trostberg, Allgemein- und Visceralchirurgie: Dr. J. Deuble; Kreisklinik Prien am Chiemsee, Chirurgische Abteilung: Prof J. Stadler. Also in particular we thank the following 21 medical hospitals and departments that participated in the documentation of $85 \%$ of the presented oncologically treated cohort: Klinik Bad Trissl, Abteilung für Innere Medizin I: Dr. B. Weber; Städt. Klinikum München-Bogenhausen, Klinik für Gastroenterologie, Hepatologie und gastrointestinale Onkologie: Prof. W. Schepp; Städt. Klinikum München-Neuperlach, Klinik für Gastroenterologie und Hepatologie: Prof. W. Schmitt; Klinikum rechts der Isar der TU, II. Medizinische Klinik: Prof. R. Schmid; Städt. Klinikum München-Harlaching, Klinik für Hämatologie, Onkologie und Palliativmedizin: Prof. M. Karthaus; Klinikum Dritter Orden, Klinik für Innere Medizin I: Prof. A. Eigler; Klinikum Rosenheim, Medizinische Klinik II: Dr. H. Huff; Städt. Klinikum München-Neuperlach, Klinik für Hämatologie und Onkologie: Prof. M. Karthaus; Klinikum Landshut, Medizinische Klinik I: Prof. A. Holstege; Klinikum Garmisch-Partenkirchen, Zentrum Innere Medizin: Prof. H.-D. Allescher, Dr. H. Lambertz; Klinikum Traunstein, Abteilung für Gastroenterologie und Hepatologie: Dr. A. Kreuzmayr; Klinikum der Ludwig-Maximilians-UniversitätGroßhadern, Medizinische Klinik und Poliklinik II: Prof. B. Göke; Klinikum Freising, Abteilung für Gastroenterologie: Prof. E. SchulteFrohlinde; Klinikum der Ludwig-Maximilians-UniversitätGroßhadern, Medizinische Klinik und Poliklinik III: Prof. W. Hiddemann; Klinikum Fürstenfeldbruck, Fachbereich Gastroenterologie und Onkologie: Prof. R. Eissele; Kreisklinik Ebersberg, Abteilung für Innere Medizin: Prof. T. Bernatik, Dr. H. L. Schneider; Klinikum Traunstein, Abteilung für Hämatologie, Onkologie und Palliativmedizin: Dr. T. W. Kubin; Klinikum München-Pasing, Medizinische Klinik II: Prof. B. Mayinger; Krankenhaus Barmherzige Brüder München, Innere Medizin I: PD Dr. C. Rust; Kreisklinik Trostberg, Innere Abteilung: Prof. T. Glück; Klinikum Ingolstadt, Medizinische Klinik II: Prof. J. Menzel.

\section{Compliance with ethical standards}

Conflict of interest The authors declare no conflict of interest.

Funding The Munich Cancer Registry (MCR) is part of the Munich Tumour Centre (TZM), of the Institute of Medical Informatics, 
Biometry and Epidemiology (IBE) and of the University Hospital of Munich. Analyses of the presented manuscript were funded by the Bundesministerium für Bildung und Forschung, BMBF (CHIR-Net, BMBF-funding no. 01GH1001C and MSZ BMBF-funding no. 01KN1104).

\section{References}

1. Robert-Koch Institute, Association of Population-based Cancer Registries, (eds.). Cancer in Germany 2007/2008. 8 ed. Contributions to Federal Health Reporting. Berlin 2012.

2. Munich Cancer Registry. [Basic Statistics: C16 Gastric Cancer]. 2013. http://www.tumorregister-muenchen.de/facts/base/base_C16_ G.pdf. Accessed 19 May 2015.

3. Nashimoto A. Current status of treatment strategy for elderly patients with gastric cancer. Int J Clin Oncol. 2013;18:969-70.

4. Endo S, Dousei T, Yoshikawa Y, Hatanaka N, Kamiike W, Nishijima J. Prognosis of gastric carcinoma patients aged 85 years or older who underwent surgery or who received best supportive care only. Int J Clin Oncol. 2013;18:1014-9.

5. Moehler M, Al-Batran SE, Andus T, Anthuber M, Arends JAD, et al. [German S3-guideline "Diagnosis and treatment of esophagogastric cancer"]. Z Gastroenterol. 2011;49:461-531.

6. Schuhmacher C, Gretschel S, Lordick F, Reichardt P, Hohenberger W, Eisenberger $\mathrm{CF}$, et al. Neoadjuvant chemotherapy compared with surgery alone for locally advanced cancer of the stomach and cardia: European Organisation for Research and Treatment of Cancer randomized trial 40954. J Clin Oncol. 2010;28:5210-8.

7. Lyman GH. Comparative effectiveness research in oncology: the need for clarity, transparency and vision. Cancer Invest. 2009;27: 593-7.

8. Hershman DL, Wright JD. Comparative effectiveness research in oncology methodology: observational data. J Clin Oncol. 2012; 30:4215-22.

9. Howlader N, Noone AM, Krapcho M, Garshell J, Neyman N, Altekruse SF et al. SEER Cancer Statistics Review, 1975-2010. 2013.

10. Dudeja V, Habermann EB, Zhong W, Tuttle TM, Vickers SM, Jensen EH, et al. Guideline recommended gastric cancer care in the elderly: insights into the applicability of cancer trials to real world. Ann Surg Oncol. 2011;18:26-33.

11. Dittmar Y, Rauchfuss F, Gotz M, Scheuerlein H, Jandt K, Settmacher U. Impact of clinical and pathohistological characteristics on the incidence of recurrence and survival in elderly patients with gastric cancer. World J Surg. 2012;36:338-45.

12. Gretschel S, Estevez-Schwarz L, Hünerbein M, Schneider U, Schlag PM. Gastric cancer surgery in elderly patients. World J Surg. 2006;30:1468-74.

13. Gockel I, Pietzka S, Gonner U, Hommel G, Junginger T. Subtotal or total gastrectomy for gastric cancer: impact of the surgical procedure on morbidity and prognosis-analysis of a 10-year experience. Langenbecks Arch Surg. 2005;390:148-55.

14. Hsu JT, Liu MS, Wang F, Chang CJ, Hwang TL, Jan YY, et al. Standard radical gastrectomy in octogenarians and nonagenarians with gastric cancer: are short-term surgical results and long-term survival substantial? J Gastrointest Surg. 2012;16:728-37.
15. Biondi A, Cananzi FC, Persiani R, Papa V, Degiuli M, Doglietto $\mathrm{GB}$, et al. The road to curative surgery in gastric cancer treatment: a different path in the elderly? J Am Coll Surg. 2012;215: 858-67.

16. Coniglio A, Tiberio GAM, Busti M, Gaverini G, Baiocchi L, Piardi T, et al. Surgical treatment for gastric carcinoma in the elderly. J Surg Oncol. 2004;88:201-5.

17. Anderson JR, Cain KC, Gelber RD. Analysis of survival by tumor response. J Clin Oncol. 1983;1:710-9.

18. Gillison TL, Chatta GS. Cancer chemotherapy in the elderly patient. Oncology (Williston Park). 2010;24:76-85.

19. Destri GL, Cavallaro M, Trovato MA, Ferlito F, Castaing M, Puleo S. Colorectal cancer treatment and follow-up in the elderly: an inexplicably different approach. Int Surg. 2012;97:219-23.

20. Kemeny MM, Busch-Devereaux E, Merriam LT, O'Hea BJ. Cancer surgery in the elderly. Hematol Oncol Clin North Am. 2000;14:169-92.

21. Lee TH, Marcantonio ER, Mangione CM, Thomas EJ, Polanczyk $\mathrm{CA}$, Cook EF, et al. Derivation and prospective validation of a simple index for prediction of cardiac risk of major noncardiac surgery. Circulation. 1999;100:1043-9.

22. Population-Based Cancer Registry Bavaria. Number of all reported new cases of cancer, incidence, cancer-related deaths, mortality (2002-2010). Erlangen 2013. http://www.krebsregisterbayern.de/PHP/Abfrage_E.php.

23. Coupland VH, Allum W, Blazeby JM, Mendall MA, Hardwick $\mathrm{RH}$, Linklater KM, et al. Incidence and survival of oesophageal and gastric cancer in England between 1998 and 2007, a population-based study. BMC Cancer. 2012;. doi:10.1186/1471-240712-11.

24. Lagergren J, Mattsson F. Diverging trends in recent populationbased survival rates in oesophageal and gastric cancer. PLoS One. 2012;. doi:10.1371/journal.pone.0041352.

25. Cancer Registry of Norway. Cancer in Norway 2009. Cancer incidence, mortality, survival and prevalence in Norway. Oslo 2011.

26. AIRTUM-Working-Group. Italian cancer figures, report 2011: Survival of cancer patients in Italy. Epidemiol Prev. 2011;35(3): $1-200$.

27. Tew WP. Considerations regarding the administration of systemic therapy for elderly patients with ovarian cancer. Curr Treat Options Oncol. 2013;14:1-11.

28. Macmillan Cancer Support, Department of Health, Age UK. Cancer Services Coming of Age: Learning from the Improving Cancer Treatment Assessment and Support for Older People Project London 2012.

29. Thompson A, Cone R, Gao H, Hammond E, Fraser D, Back MF. Is advanced age a barrier to effective cancer treatment? The experience of nonagenarians receiving radiation therapy. Asia Pac J Clin Oncol. 2012;8:255-9.

30. Saif MW, Makrilia N, Zalonis A, Merikas M, Syrigos K. Gastric cancer in the elderly: an overview. Eur J Surg Oncol. 2010;36: 709-17.

31. Baraldi-Junkins CA, Beck AC, Rothstein G. Hematopoiesis and cytokines. Relevance to cancer and aging. Hematol Oncol Clin North Am. 2000;14:45-61. 